\title{
Pediatric urologists must advocate for improved quality of care in patients with cryptorchidism
}

\author{
Rodrigo L.P. Romao, MD \\ Division of Pediatric Urology, Division of Pediatric Surgery, IWK Health Centre, Dalhousie University, Halifax, NS, Canada
}

Cite as: Can Urol Assoc J 2017;11 (1-2Suppl1):S33. http://dx.doi.org/10.5489/cuaj.4429

See related article on page $\mathbf{S 2 6}$.

$\mathrm{n}$ this review article, the authors offer a significant contribution by providing an impeccably thorough, yet concise

overview of the most current aspects of the management of cryptorchidism. Despite all the evidence summarized by the authors, our practices are still flooded with patients who have been inadequately triaged by their primary care physicians. Children with testes that are easily brought down to the scrotum and stay there are referred as having undescended testes and requiring surgery; others with a clear picture of undescended testes are counselled to wait for a few more years until they "drop;" and patients with non-palpable testis have their care delayed by useless imaging studies that also place a physical and financial strain on an already overwhelmed healthcare system.

Considering that cryptorchidism is one of the most common conditions treated by pediatric urologists, our com- munity must make every effort to educate family physicians and pediatricians on how to master the difficult craft of the testicular physical exam and define best referral practices. Initiatives like stimulating residents in the primary care specialties to come to our clinics as part of their core training and targeting this topic in continued medical education endeavors for these specialists are some examples of how the pediatric urology community can advocate for improved quality of care for little boys with this issue.

Competing interests: The author reports no competing personal or financial interests.

This paper has been peer-reviewed.

Correspondence: Dr. Rodrigo L.P. Romao, Division of Pediatric Urology, Division of Pediatric Surgery, IWK Health Centre, Dalhousie University, Halifax, NS, Canada; Rodrigo.Romao@iwk.nshealth.ca 